\title{
Canadian Association of Gastroenterology Educational Portal (ePortal)
}

\section{WHAT'S IN THE EPORTAL FOR ME?}

CAG's Educational Portal (ePortal) is a web based platform launched in 2009 to help the membership keep up to date and fulfill their education/ Maintenance of Certification (MOC) requirements.

The ePortal continues to be an invaluable tool to supplement the educational opportunities already available to CAG members (i.e. CDDW, Regional Meetings, etc). The ePortal allows members to review specific topic areas, perform short self-assessments, discuss topics with colleagues across Canada, generate ideas for personal learning projects, keep up to date with CAG events, and much more.

\section{WHY USE THE EPORTAL?}

- Utilize a large variety of tools available on the CAG ePortal

- Earn credits to meet your Maintenance of Certification learning needs while having your time on the site automatically logged to your personal ePortal profile

- Review lectures from previous meetings including CDDW

- Join interactive discussion forums

- Access key resource materials such as Clinical Practice Guidelines and position papers

MATERIALS RECENTLY ADDED TO THE EPORTAL

- 2013 GRIT Forum, in the 'Residents Corner'

- The CAG/AbbVie co-developed, Section 1 accredited, IBD Ahead Program (Module 1) with Dr Jean-Frederic Colombel.

\section{COMING SOON TO THE EPORTAL}

- Videos of the CDDW 2013 sessions

- Presentation slides/Syllabus materials from CDDW 2013

- 2012-2013 CAG National Basic Science Lecture Series Recordings

- The CAG/Shire co-developed, Expert Seminar Series: Treatment of UC; from 5-ASA to fecal transplants: evidence from the ACG, with Dr. Paul Moayyedi

- The CAG/Janssen co-developed, Expert Seminar Series: New and Old Prokinetics: The Impact of Selectivity, with Dr Carmelo Scarpignato

To access presentations, you may enter the speaker's name in the ePortal's search field, or a key word such as 'CDDW' or 'endoscopy', etc. Or you may access videos by clicking on one of the tabs from the menu bar on the main ePortal entry page.

\section{CAG RECEIVES ROYAL COLLEGE ACCREDITED CPD PROVIDER INNOVATION AWARD}

During the awards ceremony on March 3 at CDDW 2013, CAG was presented with the Royal College of Physicians and Surgeons of Canada (RCPSC) Accredited CPD Provider Innovation Award for its Educational Portal (ePortal). Dr Kevin Waschke, CAG ePortal Lead, received the award which was presented by Dr Connie Switzer on behalf of the RCPSC. The award is a tribute to the work of many from the Education Affairs and ePortal committee over the past few years.

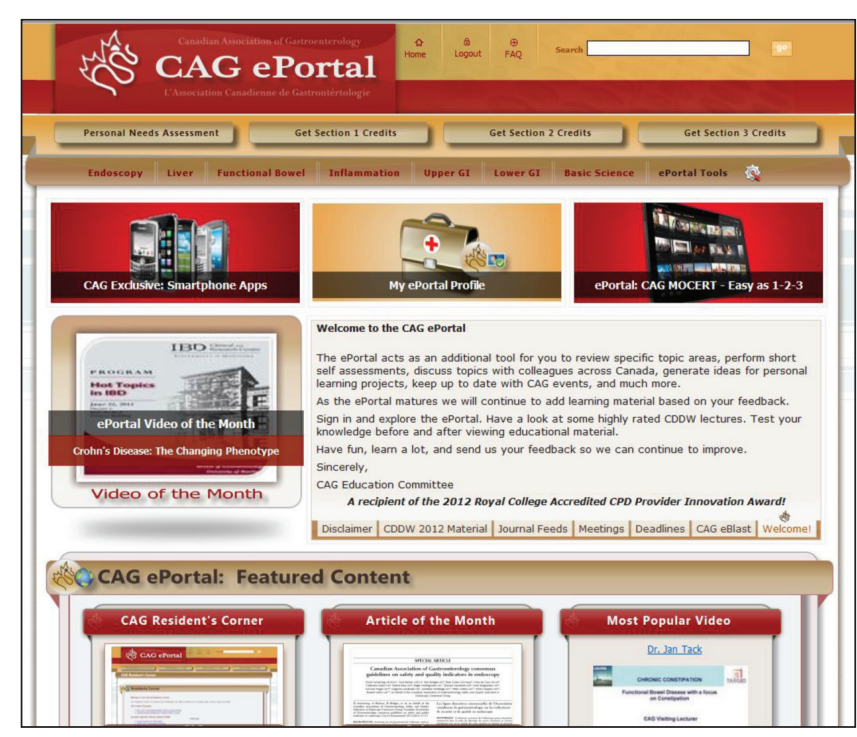

HOW TO ACCESS THE ePORTAL

Enter through a link from the CAG website at www.cag-acg.org or directly through the following link http://www.cag-eportal.org. The User Name and Password required for the ePortal is the same as your log-in for the Members page of the CAG website. Once you enter your log-in information, you may click on 'Remember Me' for immediate entry to the site on your next visit.

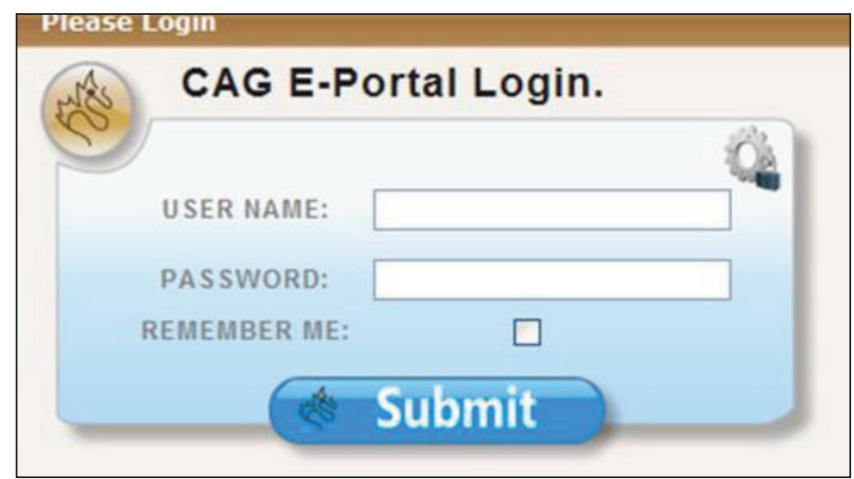

If you don't remember your log-in information, please contact the CAG office at membership@cag-acg.org.

Be sure to visit the CAG website at www.cag-acg.org for more information on CAG's ePortal and for information on the many other member benefits!

The CAG is proud to acknowledge its Benefactor Corporate Sponsors:

AbbVie Corporation

Pentax Canada Inc
Olympus Canada Inc

Janssen Inc

Takeda Canada Inc 


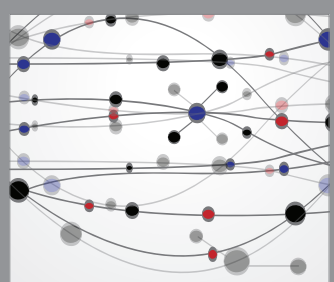

The Scientific World Journal
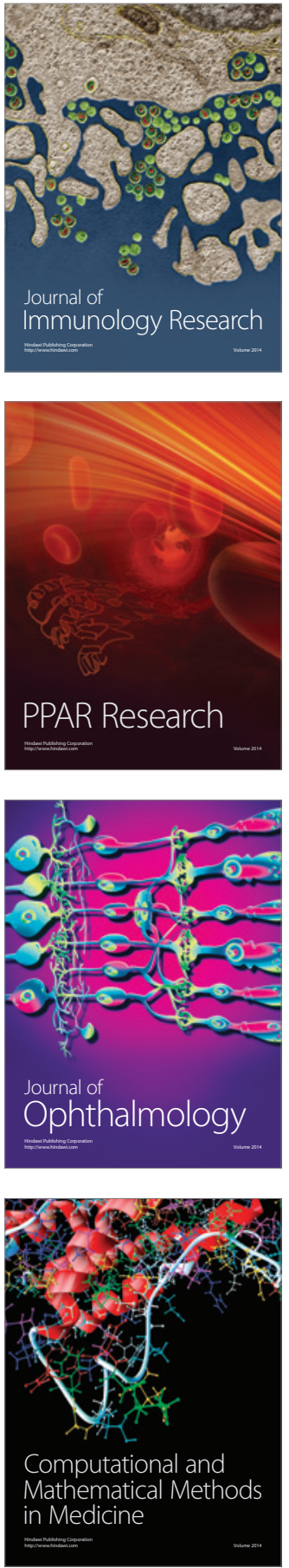

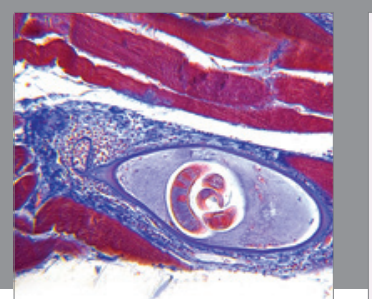

Gastroenterology Research and Practice

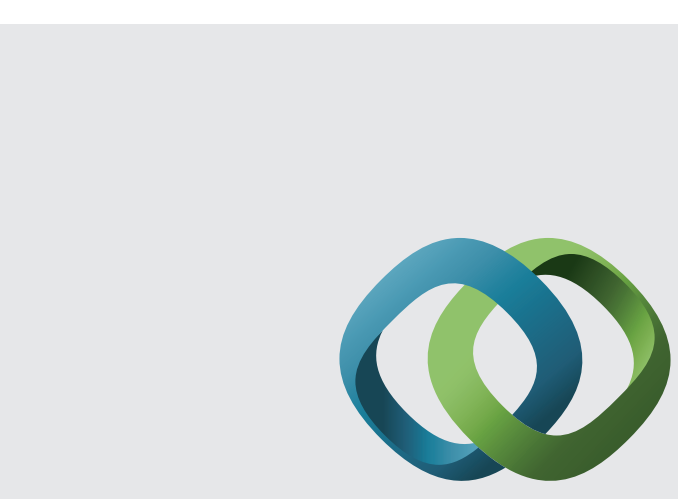

\section{Hindawi}

Submit your manuscripts at

http://www.hindawi.com
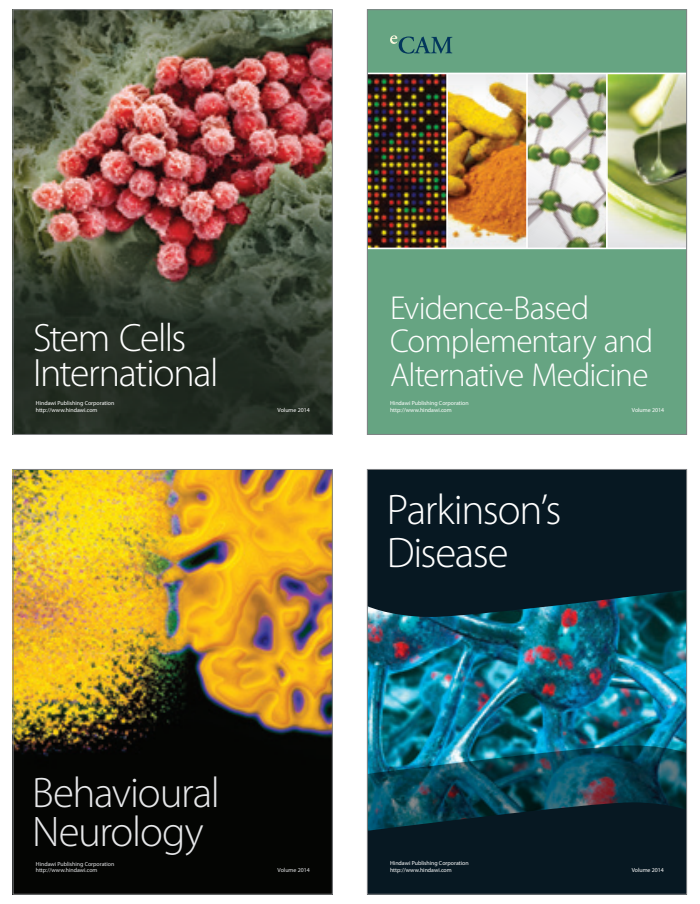
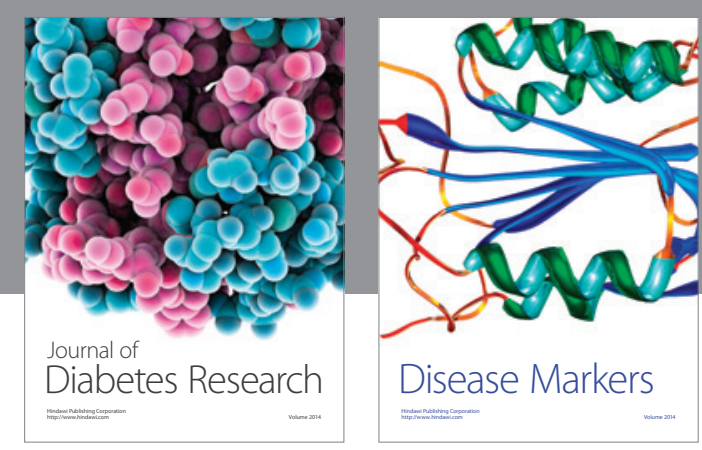

Disease Markers
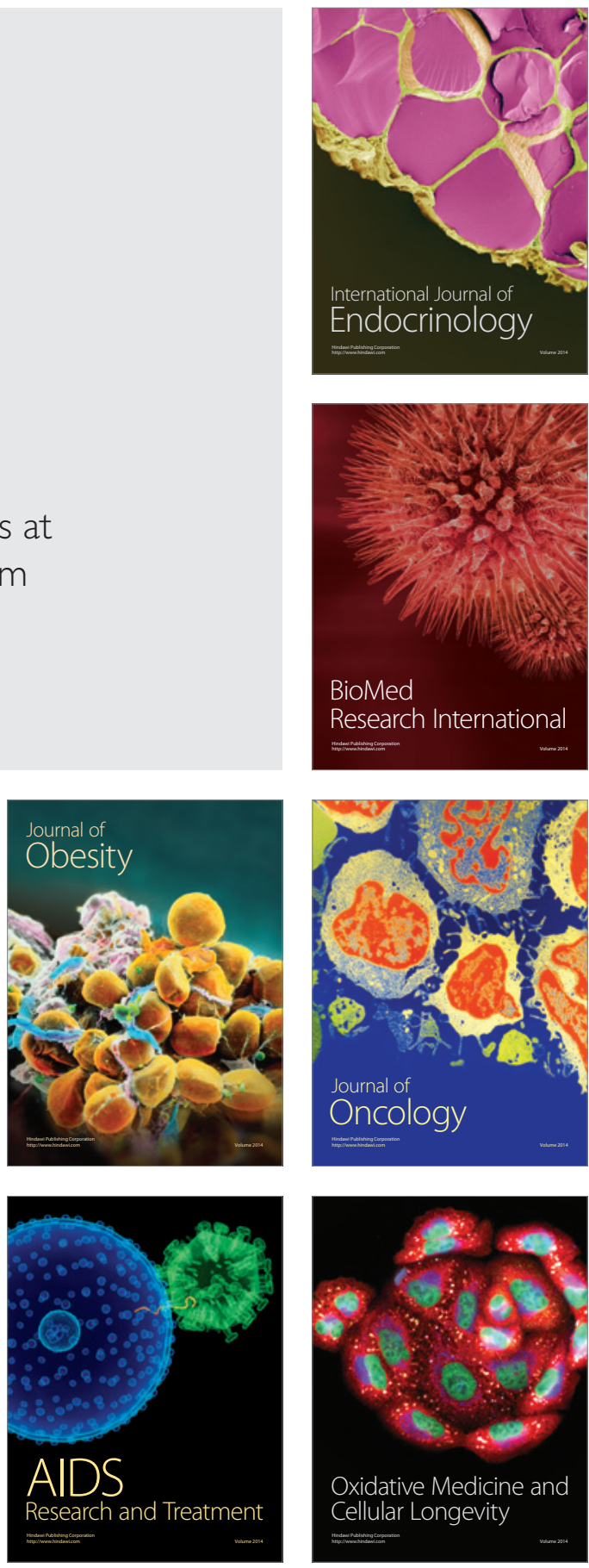